\section{THE EFFECT OF KAZUSAMYCIN ON THE GROWTH OF MURINE SOLID TUMORS AND THEIR SPONTANEOUS METASTASIS}

\author{
EISAKU Yoshida, YUKI NishimUTA, \\ KYOZO NAITO, \\ Yoshinori Watanabe, Shigeru TOMisaka \\ and AKIRA OKura \\ Exploratory Research Laboratories, \\ Banyu Pharmaceutical Co., Ltd., \\ 2-9-3 Shimomeguro, Meguro-ku, \\ Tokyo 153, Japan \\ KANKI KOMIYAMA \\ and IWAO UMEZAWA \\ The Kitasato Institute, \\ 5-9-1 Shirokane, Minato-ku, \\ Tokyo 108, Japan
}

(Received for publication September 27, 1986)

Kazusamycin (KZM) is a new antitumor antibiotic isolated from the culture broth of Streptomyces sp. No. 81-484 by UMEZAWA et al. in $1984^{1}$. Its structure was elucidated and shown to be an unsaturated branched-chain fatty acid with a terminal $\delta$-lactone by the same group ${ }^{2}$. $\mathrm{KZM}$ is a highly cytotoxic substance effective in inhibiting the growth of intraperitoneally implanted murine tumors following intraperitoneal administration ${ }^{3)}$. The antitumor specturm of KZM against such tumors is broad, and moreover, it inhibits the growth of IMC carcinoma implanted subcutaneously as described in a previous paper ${ }^{3)}$. SCHAUMBERG et al. obtained PD 114,721 which is identical with $\mathrm{KZM}^{4}$, and its antitumor activities were reported by ROBERTS et $a .^{52}$.

In the course of successive studies on KZM, we found that this agent is effective in inhibiting both the spontaneous metastasis of murine tumors as well as their growth in the implanted site. The results are presented in this report.

Lewis lung carcinoma (3LL) and melanoma B16 were used in this study. Female $\mathrm{BDF}_{1}$ mice, purchased from Shizuoka Laboratory Animal Center (Shizuoka), were subcutaneously inoculated with $5 \times 10^{5} 3 \mathrm{LL}$ or B16 cells in their inguinal area on day 0 . For dosing, KZM dissolved in dimethyl sulfoxide at appropriate concentrations was diluted 20 -fold with saline con- taining $0.6 \%$ Tween 80 , and then was injected on intermittent or on successive days. The subcutaneous tumors and lungs were taken from the mice on day 21 for $3 \mathrm{LL}$ and on day 28 for B16. The subcutaneous tumors were weighed and the number of nodules on the surface of the lungs was counted without magnification. The lungs from $3 \mathrm{LL}$-bearing mice were fixed with BouIN's solution prior to counting.

The results of two different experiments on $3 \mathrm{LL}$ are shown in Table 1 . When 0.8 or 1.6 $\mathrm{mg} / \mathrm{kg} /$ day of KZM was given every 3 days from day 1 to day 13 , the growth of subcutaneous tumors in their implanted site ("primary" tumor growth) was significantly inhibited by 31 or $42 \%$, respectively (expt 1). KZM was toxic at $3.2 \mathrm{mg} /$ $\mathrm{kg} /$ day. At autopsy, intra-intestinal bleeding was observed in every dead animal. Therefore, it was considered that the antitumor effect of KZM was dose-dependent and one of its dose-limiting factors was toxicity towards the intestines. Interestingly, the metastasis of $3 \mathrm{LL}$ to the lungs was singnificantly $(P<0.01)$ inhibited even at $0.4 \mathrm{mg} /$ $\mathrm{kg} /$ day, a dose at which the suppression of primary tumor growth was not significant. Similar results were obtained in expt 2 where KZM was injected every 4 days for 5 times. In the case of successive injection, KZM was toxic to the animals but inhibited the primary tumor growth at extremely lower doses in comparison with intermittent injections (expt 1). Moreover, metastasis was also inhibited at lower doses than those doses effective in inhibiting the growth of primary tumors, as well as those effective by intermittent injections.

The effects of KZM on the growth of B16 at the implanted site and its metastasis to lungs are shown in Table 2. KZM given intraperitoneally or intravenously at a dose of $0.67 \mathrm{mg} / \mathrm{kg} /$ day inhibited the growth of B16 subcutaneous tumor by 64 or $52 \%(P<0.001)$. Though the number of metastatic nodules was small and varied, the inhibitory effect of KZM on pulmonary metastasis was also revealed in this study. Significant inhibition was observed in a group given intraperitoneal injections of $0.67 \mathrm{mg} / \mathrm{kg} /$ day and groups given intravenous injections of 0.13 or $0.67 \mathrm{mg} / \mathrm{kg} /$ day. Lower doses of KZM also seemed to inhibit tumor metastasis even though the suppression of primary tumor growth was not observed.

According to the present study, KZM inhibits 
Table 1. The effect of KZM on the growth and the lung metastasis of 3LL implanted subcutaneously.

\begin{tabular}{|c|c|c|c|c|c|c|c|c|}
\hline & \multirow{2}{*}{ Drug $^{2}$} & \multirow{2}{*}{$\begin{array}{c}\text { Dose } \\
(\mathrm{mg} / \mathrm{kg} / \text { day })\end{array}$} & \multirow{2}{*}{$\underset{\text { (day) }}{\text { Schedule }}$} & \multirow{2}{*}{ Died/All ${ }^{b}$} & \multicolumn{2}{|c|}{ Tumor weight } & \multicolumn{2}{|c|}{ No. of pulmonary nodules } \\
\hline & & & & & Mean $(\mathrm{g}) \pm \mathrm{SD}$ & Inhibition $(\%)$ & Mean $\pm S D$ & Inhibition $(\%)$ \\
\hline \multirow[t]{11}{*}{ Expt 1} & Control & - & $1,4,7,10,13$ & $0 / 16$ & $4.62 \pm 1.38$ & 0 & $75 \pm 44$ & 0 \\
\hline & $\mathrm{KZM}$ & $0.4 \times 5$ & $1,4,7,10,13$ & $0 / 7$ & $3.79 \pm 0.63$ & 17 & $28 \pm 19^{* *}$ & 63 \\
\hline & & $0.8 \times 5$ & $1,4,7,10,13$ & $0 / 8$ & $3.16 \pm 0.95^{*}$ & 31 & $24 \pm 16^{* *}$ & 68 \\
\hline & & $1.6 \times 5$ & $1,4,7,10,13$ & $0 / 8$ & $2.66 \pm 0.44 * * *$ & 42 & $11 \pm 6^{* * *}$ & 85 \\
\hline & & $3.2 \times 5$ & $1,4,7,10,13$ & $8 / 8$ & & & & \\
\hline & & $0.0063 \times 5$ & $1 \sim 5$ & $0 / 8$ & $3.82 \pm 1.14$ & 17 & $39 \pm 21$ & 48 \\
\hline & & $0.0125 \times 5$ & $1 \sim 5$ & $1 / 8$ & $4.73 \pm 0.72$ & -2 & $41 \pm 22^{*}$ & 45 \\
\hline & & $0.025 \times 5$ & $1 \sim 5$ & $2 / 8$ & $3.58 \pm 1.05$ & 22 & $38 \pm 26^{*}$ & 49 \\
\hline & & $0.05 \times 5$ & $1 \sim 5$ & $5 / 7$ & 2.77 & 40 & 40 & 47 \\
\hline & Mitomycin $\mathrm{C}$ & $0.2 \times 5$ & $1 \sim 5$ & $0 / 8$ & $2.69 \pm 0.93^{* *}$ & 42 & $29 \pm 19^{* *}$ & 61 \\
\hline & & $1 \times 5$ & $1 \sim 5$ & $0 / 8$ & $1.84 \pm 0.57^{* * *}$ & 60 & $30 \pm 22^{* *}$ & 60 \\
\hline \multirow[t]{5}{*}{ Expt 2} & Control & - & $1,5,9,13,17$ & $0 / 17$ & $7.11 \pm 1.62$ & 0 & $120 \pm 64$ & 0 \\
\hline & KZM & $0.027 \times 5$ & $1,5,9,13,17$ & $0 / 8$ & $5.83 \pm 1.83$ & 17 & $122 \pm 64$ & -2 \\
\hline & & $0.13 \times 5$ & $1,5,9,13,17$ & $0 / 8$ & $7.21 \pm 0.89$ & -1 & $96 \pm 52$ & 20 \\
\hline & & $0.67 \times 5$ & $1,5,9,13,17$ & $0 / 8$ & $5.35 \pm 2.12 *$ & 24 & $30 \pm 24 * *$ & 75 \\
\hline & Mitomycin C & $1 \times 5$ & $1,5,9,13,17$ & $0 / 8$ & $4.19 \pm 1.24 * * *$ & 41 & $60 \pm 49 * *$ & 50 \\
\hline
\end{tabular}

a $\mathrm{BDF}_{1}$ mice were implanted with $5 \times 10^{5} 3 \mathrm{LL}$ cells on day 0 and given intraperitoneal injection of drug on the days indicated in the table.

b No. of mice died until day $21 /$ No. of mice tested.

* $P<0.05,{ }^{* *} P<0.01,{ }^{* * *} P<0.001$ by statistical t-test (tumor weight) or $\mathrm{U}$-test (pulmonary nodules). 
Table 2. The effect of KZM on the tumor growth and the lung metastasis of B16 implanted subcutaneously.

\begin{tabular}{|c|c|c|c|c|c|c|}
\hline \multirow[b]{2}{*}{ Druga } & \multirow{2}{*}{$\begin{array}{c}\text { Dose } \\
(\mathrm{mg} / \mathrm{kg} / \mathrm{day})\end{array}$} & \multirow[b]{2}{*}{ Route } & \multicolumn{2}{|c|}{ Tumor weight } & \multicolumn{2}{|c|}{ No. of pulmonary nodules } \\
\hline & & & Mean $(\mathrm{g}) \pm \mathrm{SD}$ & $\begin{array}{c}\text { Inhibition } \\
(\%)\end{array}$ & Mean $\pm S D$ & $\begin{array}{c}\text { Inhibition } \\
(\%)\end{array}$ \\
\hline Control & - & ip & $5.30 \pm 1.26$ & 0 & $5.6 \pm 9.0$ & 0 \\
\hline \multirow[t]{3}{*}{ KZM } & $0.027 \times 5$ & & $4.90 \pm 1.57$ & 7 & $1.0 \pm 1.8$ & 82 \\
\hline & $0.13 \times 5$ & & $4.25 \pm 1.50$ & 20 & $0.3 \pm 0.5$ & 95 \\
\hline & $0.67 \times 5$ & & $1.90 \pm 0.95^{* * *}$ & 64 & $0.1 \pm 0.4^{* *}$ & 98 \\
\hline Mitomycin C & $1 \times 5$ & & $2.86 \pm 0.65^{* * * *}$ & 46 & $0.4 \pm 0.5^{*}$ & 93 \\
\hline \multirow[t]{3}{*}{$\mathrm{KZM}$} & $0.027 \times 5$ & iv & $4.42 \pm 1.57$ & 17 & $2.0 \pm 0.8$ & 64 \\
\hline & $0.13 \times 5$ & & $4.98 \pm 1.40$ & 6 & $0.5 \pm 1.1 *$ & 91 \\
\hline & $0.67 \times 5$ & & $2.52 \pm 1.60 \% *$ & 52 & $0.1 \pm 0.4^{* *}$ & 98 \\
\hline Mitomycin C & $1 \times 5$ & & $2.17 \pm 0.82 * * *$ & 59 & $0.0^{* *}$ & 100 \\
\hline
\end{tabular}

a Drugs were ip or iv injected on day $1,5,9,13$ and 17 (control $n=18$, test $n=8$ ).

* $P<0.05,{ }^{* *} P<0.01,{ }^{* * *} P<0.001$ by statistical t-test (tumor weight) or U-test (pulmonary nodules).

the spontaneous metastasis of $3 \mathrm{LL}$ and $\mathrm{B} 16$ to lungs at low doses which are not sufficient to inhibit the growth of primary tumors. The mechanism of metastasis inhibition is unclear, but it is conceivable that (a) the tissue distribution of administered KZM may relate to it, and (b) $\mathrm{KZM}$ may have a unique action on tumor cells. These investigations are now in progress, and the results will be reported elsewhere.

\section{References}

1) Umezawa, I.; K. Komiyama, H. OKA, K. OKadA, S. TOMISAKa, T. Mryano \& S. TAKano: A new antitumor antibiotic, kazusamycin. J. Antibiotics 37: 706 711, 1984

2) KomiYaMA, K.; K. OKadA, H. OKa, S. TOMISAKa, T. MiYano, S. FunaYama \& I. UMEZAWA:
Structural study of a new antitumor antibiotic, kazusamycin. J. Antibiotics 38: 220 223, 1985

3) Komiyama, K.; K. Okada, Y. Hirokawa, K. Masuda, S. Tomisaka \& I. Umezawa: Antitumor activity of a new antibiotic, kazusamycin. J. Antibiotics 38: 224 229, 1985

4) SchaumberG, J. P.; G. C. Hokanson \& J. C. FRENCH: The structures of the antitumor antibiotics, PD 114720 and PD 114721. J. Chem. Soc. Chem. Commun. 1984: 1450 1452, 1984

5) Roberts, B. J.; K. L. Hamelehle, J. S. Sebolt \& W. R. LEOPOLD: In vivo and in vitro anticancer activity of the sructurally novel and highly potent antibiotic Cl-940 and its hydroxy analog (PD 114,721). Cancer Chemother. Pharmacol. 16: 95 101, 1986 